\title{
Review
}

\section{$11 \beta$-Hydroxysteroid dehydrogenase Type 1 in obesity and Type 2 diabetes}

\author{
T. M. Stulnig' ${ }^{1,2}$, W. Waldhäus $\mathbf{l}^{1,2}$ \\ ${ }^{1}$ Division of Endocrinology and Metabolism, Department of Internal Medicine III, University of Vienna, Vienna, Austria \\ ${ }^{2}$ Center of Molecular Medicine of the Austrian Academy of Sciences, Vienna, Austria
}

\begin{abstract}
Obesity and Type 2 diabetes mellitus are associated with abnormal regulation of glucocorticoid metabolism that are highlighted by clinical similarities between the sequelae of insulin resistance and Cushing's syndrome, as well as glucocorticoids' functional antagonism to insulin. 11ß-hydroxysteroid dehydrogenase type 1 (11 $\beta$-HSD1) activates functionally inert glucocorticoid precursors (cortisone) to active glucocorticoids (cortisol) within insulin target tissues, such as adipose tissue, thereby regulating local glucocorticoid action. Recent data, mainly from rodents, provide considerable evidence for a causal role of $11 \beta$-HSD1
\end{abstract}

for the development of visceral obesity and Type 2 diabetes though data in humans are not unequivocal. This review summarizes current evidence on a possible role of $11 \beta$-HSD1 for development of the metabolic syndrome, raising the possibility of novel therapeutic options for the treatment of Type 2 diabetes by inhibition or down-regulation of 11 $\beta$-HSD1 activity. [Diabetologia (2004) 47:1-11]

Keywords Hydroxysteroid dehydrogenase - hydrocortisone · glucocorticoids · visceral obesity · diabetes mellitus $\cdot$ insulin resistance $\cdot$ adipose tissue $\cdot$ intra-abdominal fat · pituitary-adrenal system · Cushing's syndrome
Obesity has become an epidemic in the western world and is tightly associated with Type 2 diabetes mellitus and other manifestations of the metabolic syndrome $[1,2]$. The metabolic syndrome comprises a variety of disorders including Type 2 diabetes and hyperlipidaemia that relate to a loss of insulin sensitivity in important target tissues such as adipose tissue, muscle and liver $[1,3]$. Upper-body (android) obesity—measured

Received: 10 June 2003 / Revised: 29 October 2003

Published online: 3 December 2003

(C) Springer-Verlag 2003

T. M. Stulnig ( $)$, Division of Endocrinology and Metabolism, Department of Internal Medicine III, University of Vienna, Währinger Gürtel 18-20, A-1090 Vienna, Austria

E-mail: Thomas.Stulnig@akh-wien.ac.at

Abbreviations: 11 $\beta$-HSD1, 11 $\beta$-hydroxysteroid dehydrogenase type 1; HPA, hypothalamic-pituitary-adrenal; LXR, liver X receptor; PEPCK, phosphoenolpyruvate carboxykinase; PPAR, peroxisome proliferator-activated receptor; GR, glucocorticoid receptor; H6PDH, hexose-6-phosphate dehydrogenase. by increased waist-to-hip ratio-rather than lowerbody (gynoid) obesity is associated with glucose intolerance and other features of the metabolic syndrome, and represents an important predictor for increased morbidity and mortality, not only from diabetes but also from coronary heart disease and certain cancers [4]. Although the WHR encompasses both intra-abdominal (visceral) and abdominal subcutaneous adipose depots, more detailed studies emphasize the importance of the visceral component for the development of metabolic disorders [4]. A causal relationship of visceral obesity for insulin resistance was recently demonstrated by surgical removal of visceral (epididymal and perinephric) fat pads of obese Sprague-Dawley rats that markedly improved hepatic insulin sensitivity and reduced hepatic glucose production [5].

A number of theories have been introduced to explain the close association of Type 2 diabetes mellitus and visceral obesity. Beyond genetic factors determining fat distribution and overeating as a common cause for both obesity and Type 2 diabetes, direct venous 
drainage of visceral adipose tissue to the liver and distinct regional differences of adipocyte biology could play an important role for the development of the metabolic syndrome [4]. One distinctive feature of visceral adipose tissue is its particular responsiveness to glucocorticoids. Not only do visceral adipocytes express higher numbers of glucocorticoid receptors [6], also the local interconversion of inactive glucocorticoid precursors into active glucocorticoids appears considerably more pronounced in visceral than in subcutaneous adipose tissue [7]. This reaction is catalyzed by the $11 \beta$-hydroxysteroid dehydrogenase Type 1 (11ßHSD1), which converts cortisone to cortisol. Thus, the association of visceral adipose tissue and insulin resistance could be provoked by regionally altered steroid responsiveness with $11 \beta-H S D 1$ playing a central role.

\section{Insulin antagonism of glucocorticoids}

Glucocorticoids are functional antagonists of insulin action. They impair insulin-dependent glucose uptake and increase lipolysis, enhance hepatic gluconeogenesis and provide substrates by promoting proteolysis [8], and directly inhibit insulin secretion from pancreatic beta cells $[9,10,11]$. Whereas insulin inhibits hepatic gluconeogenesis, glucocorticoids enhance glucose production in the liver both directly by transactivating crucial genes involved in this process and indirectly by stimulation of other hormones, e.g. glucagon. Hepatic expression of the gene for phosphoenolpyruvate carboxykinase (PEPCK), the enzyme catalyzing the rate-limiting step in gluconeogenesis is regulated by a strong glucocorticoid response unit and is also responsive to the cAMP regulatory element binding protein (CREB) [12]. Glucocorticoids and CREB synergistically induce peroxisome proliferator-activated receptor- $\gamma$ coactivator-1 (PGC-1), a key activator of hepatic gluconeogenesis [13, 14]. In addition, glucocorticoids oppose other metabolic insulin actions including insulin signalling and inhibit insulin-stimulated glucose uptake by inhibiting the translocation of the glucose transporter GLUT4 to the plasma membrane [15].

Opposing effects of glucocorticoids to insulin action are also evident in clinical situations. Patients with Cushing's syndrome have a lower maximal glucose disposal rate during hyperinsulinaemic clamp studies compared to control subjects. Insulin-dose-response curves are shifted to the right in patients with Cushing's syndrome disclosing insulin resistance [16] and up to $20 \%$ develop impaired glucose tolerance or frank diabetes. Moreover, treatment with glucocorticoids decreases insulin sensitivity and exacerbates hyperglycaemia in diabetic patients [17]. On the other hand, insulin opposes glucocorticoid action as shown by the fact that increased insulin sensitivity during intensive treatment for Type 2 diabetes decreases glucocorticoid re- ceptor expression in skeletal muscle [18]. Thus, decreased insulin sensitivity could release glucocorticoid sensitivity from insulin-mediated inhibition and favour a downward spiral of insulin sensitivity along with increasing glucocorticoid responsiveness.

In addition to the functional antagonism of insulin and glucocorticoids, there are striking clinical similarities between Cushing's syndrome and the metabolic syndrome $\mathrm{X}$ that point to a common underlying mechanism [11]. Besides insulin resistance, both syndromes share hypertension, visceral obesity, hyperlipidaemia and glucose intolerance up to overt diabetes mellitus. However, circulating glucocorticoid concentrations are commonly not increased in obesity or Type 2 diabetes.

\section{1/-HSD1: expression and function}

Prereceptor regulation of glucocorticoid action. The main determinants of steroid action were formerly thought to be their plasma concentrations, the extent of binding to plasma proteins and the density of their receptors in target tissues. In addition, enzymes modifying hormone chemistry in target tissues exist for a variety of hormones that bind to nuclear receptors, e.g. 5 $\alpha$-reductase for the androgen and 5'-monoiodinases for thyroid hormones [19]. These prereceptor pathways potently modulate the local hormone concentration and action. For glucocorticoids, chemical residues at the 11-position, either $11 \beta$-hydroxy or 11oxo moieties, determine whether or not steroids are able to bind to glucocorticoid (and mineralocorticoid) receptors. Glucocorticoid receptor binding is restricted to steroids with $11 \beta$-hydroxyl moieties, i.e. mainly cortisol in humans and corticosterone in rodents, respectively. The responsible proteins, the $11 \beta$-hydroxysteroid dehydrogenases (11 $\beta$-HSD), exist in two isoforms with only $21 \%$ identity [20] (Fig. 1). 11 $\beta$ HSD type 2 is predominantly expressed in kidney and catalyses the $11 \beta$-dehydrogenase reaction that rapidly inactivates active glucocorticoids (cortisol, corticosterone) by converting to cortisone or 11-dehydro-corticosterone, respectively, to ensure selectivity of the mineralocorticoid receptor. On the other hand, $11 \beta$ HSD1 activates inert precursors (cortisone, 11-dehydro corticosterone) to active glucocorticoids by oxoreductase activity in liver, adipose tissue, brain, skeletal muscle, vascular smooth muscle cells and other organs [21]. Though $11 \beta$-HSD1 appears to act as an oxo-reductase in most if not all instances, recent reports suggest the possibility of a switch to the $11 \beta$ dehydrogenase reaction by the same enzyme with the direction of the reaction being regulated, e.g., by the state of cellular differentiation and endoplasmic redox potential, as discussed below. For readers' convenience, this review consistently refers to the glucocorticoid-activating oxo-reductase reaction when speaking of $11 \beta$-HSD1 activity. 
<smiles>CC(=O)OC1CCC2C3CCC(O)(C(C)=O)C3(C)CC(=O)[C@@H]2C12C=CC(O)CC2</smiles>
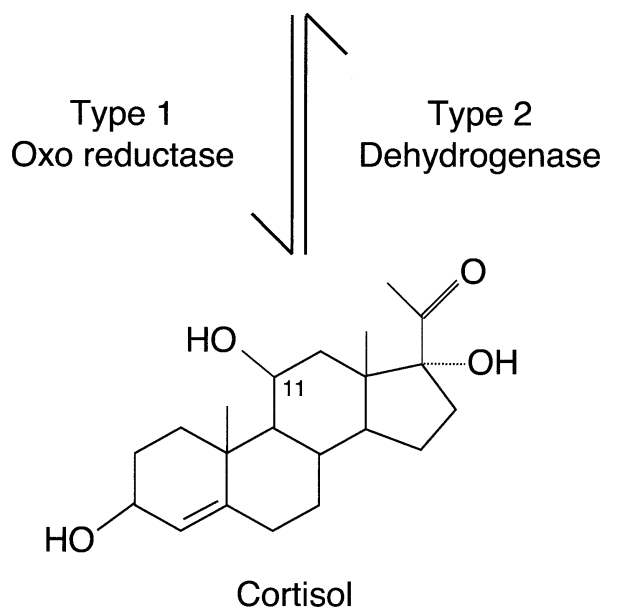

Fig. 1. Interconversion of cortisone and cortisol as catalysed by $11 \beta$-HSD type 1 and 2 . 11 -HSD1 usually acts as oxo-reductase but can also catalyse the $11 \beta$-dehydrogenase reaction as discussed in the text

During diurnal nadir, only approximately $5 \%$ of cortisol circulates unbound in a thermodynamically "free" form to access glucocorticoid receptors, whereas most cortisol is bound to corticosteroid-binding globulin or albumin in blood plasma. Since these binding proteins are saturated by high-physiological concentrations of cortisol, considerable variations of free plasma cortisol concentrations occur during diurnal changes (1-100 nmol/1) [21]. In contrast, cortisone, the main 11oxo steroid in human plasma, circulates at about 50 to $100 \mathrm{nmol} / \mathrm{l}$, does not have a pronounced diurnal variation and is barely protein-bound resulting in continuously higher "free" plasma concentrations compared to cortisol [22]. Thus, plasma cortisone can be regarded as an inactive glucocorticoid storage pool that is constantly provided to $11 \beta-\mathrm{HSD} 1$ reductase to maintain local active glucocorticoid concentrations even in periods of low plasma cortisol concentrations, e.g. during the diurnal nadir. By expression of $11 \beta-H S D 1$, the target tissue itself is equipped to regulate its own glucocorticoid concentration and subsequently its glucocorticoid responsiveness on the prereceptor level by adjusting the rate of local glucocorticoid activation [23]. This is of particular interest in metabolically active tissues where glucocorticoids functionally oppose insulin action.

Regulation of $11 \beta$-HSD1 expression. Though cortisol is the product of $11 \beta$-HSD1 action, it also stimulates
$11 \beta$-HSD1 expression in hepatocytes, adipocytes and myoblasts [24, 25]. Cortisol induces adipogenesis and $11 \beta$-HSD 1 activity in preadipocytes whereby $11 \beta$ HSD1 could well contribute to adipocyte differentiation by converting cortisone to cortisol $[25,26]$. Induction of $11 \beta$-HSD1 by 11-dehydro glucocorticoids such as cortisone provides a positive feedback loop [27] that is attenuated by down-regulation of the ligand-binding and transactivating glucocorticoid receptor (GR) $\alpha$ [28] and stimulated by parallel expression of GR $\beta$, a dominant negative regulator of GR $\alpha$ [29].

Insulin seems to down-regulate 11ß-HSD1 activity but data are not unequivocal at this point. In human adipose stromal cells (i.e. preadipocytes) insulin attenuates 11ß-HSD1 activity and similar results were found in fibroblasts, hepatoma cells, and myoblasts, depending on culture conditions [30, 31]. However, insulin synergises with glucocorticoids to stimulate adipocyte differentiation that is associated with the induction of $11 \beta$-HSD1 activity [25].

In addition, other hormones and cytokines are able to regulate $11 \beta$-HSD1 activity. Growth hormone/IGF1 reduces $11 \beta$-HSD 1 activity [32], whereas TNF $\alpha$, IL$1 \beta$ and IL-6 increase $11 \beta$-HSD1 expression at least in adipose stromal cells [33]. Up-regulation by TNF $\alpha$ is particularly interesting in that $\mathrm{TNF} \alpha$ seems to reduce insulin sensitivity in adipose tissue. Since insulin itself counteracts the stimulatory effect of TNF $\alpha$ [34], a vicious circle could be postulated with lower insulin sensitivity being less able to abolish TNF-driven $11 \beta$ HSD1 up-regulation. Thereby, stimulation of $11 \beta$ HSD1 activity by TNF $\alpha$ could be a means for a selfpotentiating negative effect on insulin sensitivity. Notably, also estrogens can suppress $11 \beta$-HSD1 expression possibly contributing to their metabolic and cardiovascular effects in premenopausal women [35].

Only scarce data are available on regulation of expression of the HSD11B1 gene (encoding 11 $\beta$-HSD1) at the molecular level although the rat promoter has been cloned years ago [36]. At least in rat liver cells, CCAAT/enhancer binding protein (C/EBP) $\alpha$ is an important factor for $H S D 11 B 1$ transcription [37]. In murine adipocytes, typical transcription factors associated with adipocyte differentiation, such as peroxisome proliferator-activated receptor (PPAR) $\gamma$ and liver X receptors (LXR) repress 11 $\beta$-HSD1 expression by unknown molecular mechanisms [38]. Differential expression of $11 \beta$-HSD1 in omental compared to subcutaneous preadipocytes and adipocytes could be due to differences in transcription factor and cofactor binding but molecular data are still lacking.

\section{1 $\beta$-HSD1 in adipocyte biology}

Switch in 11 $\beta$-HSD1 expression during adipogenesis. $11 \beta$-HSD1 but not $11 \beta$-HSD2 is expressed in human preadipocytes but there are considerable site-specific 


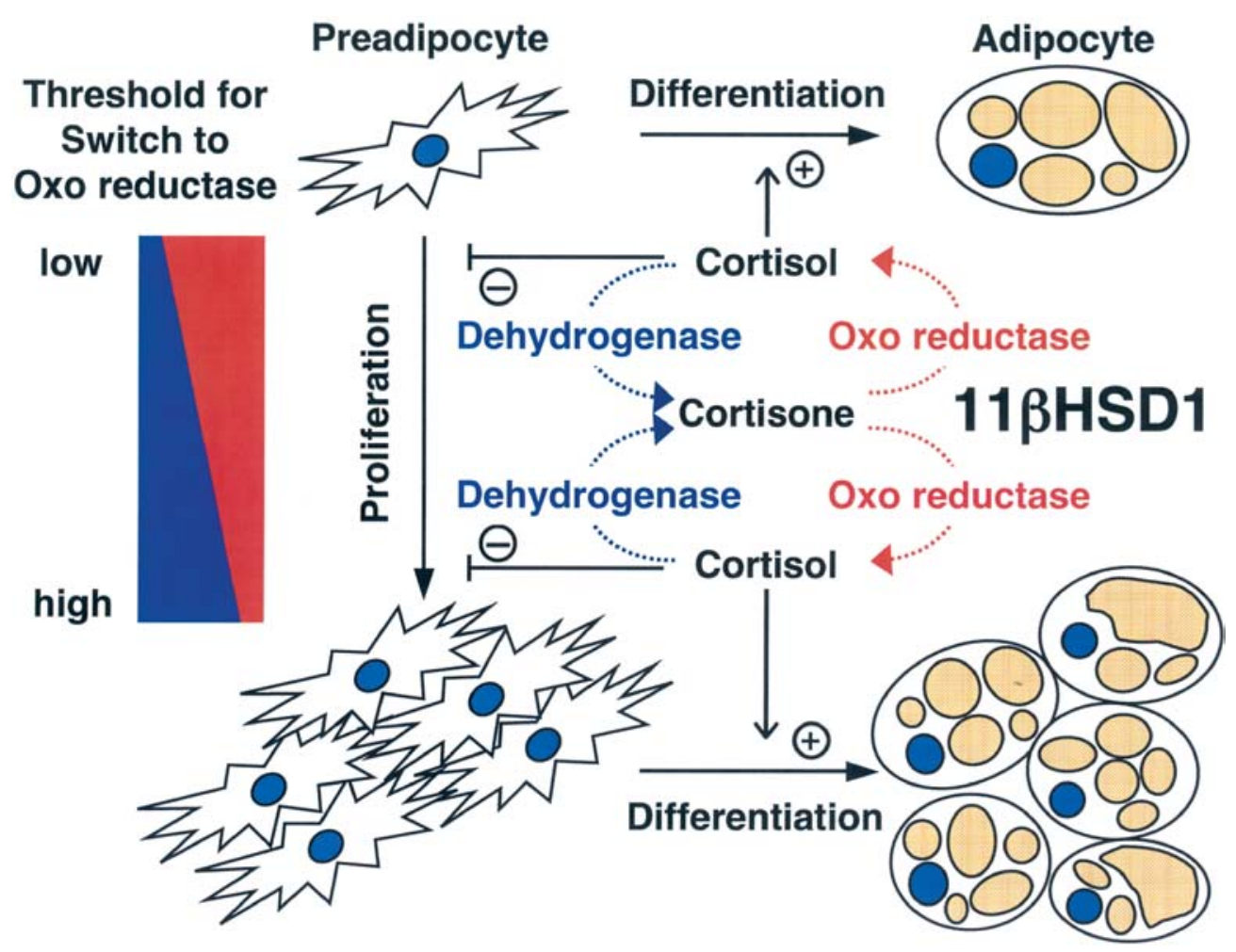

Fig. 2. How an altered threshold for the switch from 11ß-dehydrogenase to oxo-reductase reaction catalysed by $11 \beta$-HSD 1 could influence adipose tissue biology. Recent data suggest a switch of $11 \beta$-HSD1 from $11 \beta$-dehydrogenase to oxo-reductase reaction during differentiation of visceral preadipocytes [39]. The threshold for this switch seems to be higher in visceral preadipocytes from obese compared to non-obese subjects as discussed in the text. $\rightarrow$, chemical reaction catalysed by $11 \beta$-HSD 1

differences depending on whether preadipocytes were isolated from visceral or subcutaneous fat depots [7]. Preadipocytes from visceral adipose tissue express markedly more 11ß-HSD1 mRNA and oxo-reductase activity than subcutaneous adipose stromal cells when preadipocytes were cultured for more than 10 days [7]. Taking a closer view on freshly isolated human preadipocytes from omental origin, 11ß-HSD1 appears to predominantly catalyse the $11 \beta$-dehydrogenase reaction thereby inactivating cortisol to cortisone, whereas the glucocorticoid-activating oxo-reductase reaction predominates during adipocyte differentiation only of omental but not of subcutaneous adipose stromal cells [39]. Notably, 11ß-HSD1 mRNA changes only minimally during differentiation of human adipose stromal cells [39] in contrast to murine preadipocyte cell lines that do not express $11 \beta$-HSD1 until terminally differentiated into adipocytes [40]. However, data showing 11 $\beta$ dehydrogenase activity have to be taken with caution since $11 \beta$-dehydrogenase activity of $11 \beta$-HSD1 is characteristic for the isolated enzyme located outside intact cells and is hence generally regarded as an indicator of cellular destruction. Nevertheless, a switch from $11 \beta$ - dehydrogenase to oxo-reductase activity of 11 $\beta$-HSD1 could be caused by altered redox potentials due to changes in microsomal NADPH:NADP ${ }^{+}$ratio [39]. The switch from dehydrogenase to oxo-reductase activity during human preadipocyte differentiation is accompanied by up-regulation of hexose-6-phosphate dehydrogenase (H6PDH) [41]. H6PDH can catalyse the first to steps of the pentose phosphate pathway to generate NADPH thereby regulating the microsomal redox potential. The critical role of H6PDH for 11ß-HSD1 oxoreductase activity is underlined by the fact that $H 6 P D$ mutations together with $H S D 11 B 1$ mutations are associated with human cortisone reductase deficiency [41].

If a change from $11 \beta$-dehydrogenase to oxo-reductase activity occurs during adipogenesis in visceral adipose tissue, the set point of the switch could have a considerable effect on the development of visceral obesity (Fig. 2) [39]. Adipose tissue hypertrophy depends on proliferation of preadipocytes, their differentiation to adipocytes and increase in adipocyte size by lipid accumulation. Cortisol adds to that process in that it inhibits cellular proliferation but strongly promotes adipocyte differentiation $[26,42]$. Hence, cortisol-inactivating $11 \beta$-dehydrogenase activity of $11 \beta$ HSD1 in preadipocytes could facilitate their proliferation and protect themselves from differentiation to adipocytes in an autocrine fashion. Generation of cortisol by a switch to oxo-reductase activity during early differentiation of visceral adipocytes then promotes terminal adipogenesis. Since GR $\alpha$ expression is markedly higher in visceral compared to subcutaneous adipose tissue [43], the differentiating effect of glucocorticoids is supposed to be more pronounced in visceral 
adipose tissue. Thus, the set-point for the switch from $11 \beta$-dehydrogenase to oxo-reductase activity could be of considerable importance for the development of visceral obesity [44]. Moreover, cortisone to cortisol conversion could possibly also act in a paracrine fashion, i.e. that differentiation to adipocytes in visceral adipose tissues could inhibit proliferation and facilitate differentiation of neighboring preadipocytes.

$11 \beta$-HSD1 in genetically altered mice. The most striking evidence for both a physiological and pathophysiological role of $11 \beta$-HSD1 for insulin sensitivity and diabetes comes from genetically altered mice. $11 \beta$ HSD1 knockout mice not only showed that 11ß-HSD1 is the sole major $11 \beta$-reductase [45]. Despite slightly increased basal corticosterone concentrations that are due to diminished negative feedback inhibition of the hypothalamic-pituitary-adrenal axis [46], 11 $\beta$-HSD $1^{-1-}$ mice show impaired induction of hepatic gluconeogenetic enzymes (PEPCK, glucose-6-phosphatase) during fasting and a mitigated glycaemic response to stress or induction of obesity [45]. Glucose tolerance is improved in $11 \beta-H S D 1^{-/-}$mice. Increased hepatic insulin sensitivity in $11 \beta-H S D 1^{-/-}$mice is emphasised by lower plasma glucose concentrations at $24 \mathrm{~h}$ upon refeeding and an exaggerated hepatic induction of genes for lipogenic enzymes [47]. These findings reveal an impaired intracellular activation of glucocorticoids in $11 \beta-\mathrm{HSD}^{-/-}$mice that antagonises insulin action under physiological conditions.

To analyse the effect of increased expression of $11 \beta$-HSD1 in adipose tissue as it occurs in obesity, transgenic mice were generated with the 11ß-HSD1 gene driven by the adipocyte-specific fatty acid binding protein ( $\mathrm{aP} 2$ ) promoter [43]. Transgenic mice showed visceral obesity with predominant hypertrophy of the mesenterial fat depots that exhibit higher GR $\alpha$ expression. Notably, the transgene was expressed only two to threefold more pronounced than in the control animals and hence corresponded well to $11 \beta$-HSD1 expression in other models of obesity. Corticosterone concentrations in adipose tissues and the portal vein were increased in such transgenic animals compared to non-transgenic control animals, whereas circulating corticosterone concentrations remained unaltered. Notably, overexpression of $11 \beta-H S D 1$ solely in adipose tissue resulted in whole body insulin resistance exemplified by an abnormal plasma glucose response to i.v. glucose injection, diminished reduction plasma glucose by insulin and increase plasma NEFA. However, the aP2 promoter is activated only in adipocytes but not in preadipocytes. Hence, adipose tissue hypertrophy in $11 \beta$-HSD1 transgenic animals was due to increased adipocyte size only, whereas adipose tissue hypertrophy in obesity is due to a combination of increased adipocyte size and preadipocyte hyperplasia. Thus, this elegant paper [43] elucidated the effect of $11 \beta$-HSD1 in adipocytes but the consequences of

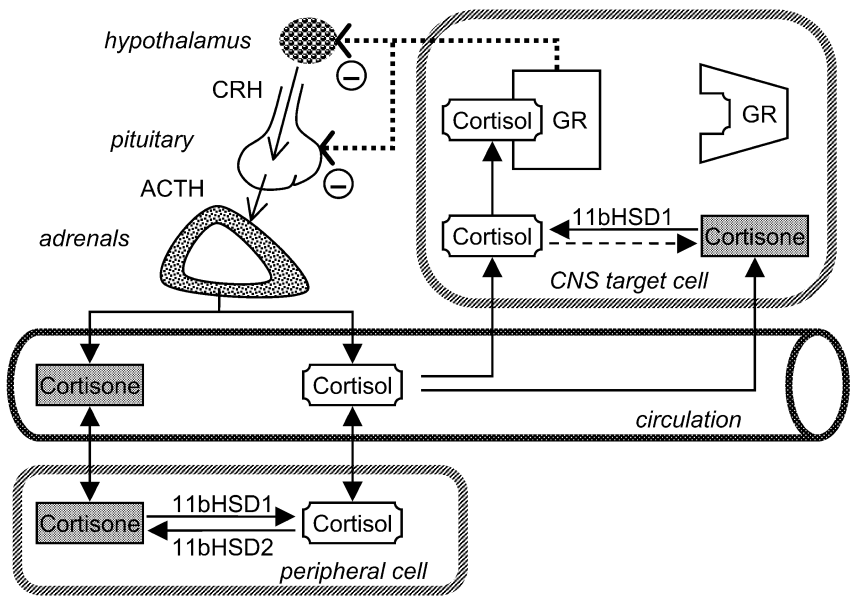

Fig. 3. Implication of $11 \beta$-HSDs for glucocorticoid feedback regulation within the hypothalamic-pituitary-adrenal axis. Cortisol synthesis in the adrenals is regulated by the hypothalamic-pituitary-adrenal axis. Cortisol is also generated from cortisone in 11 $\beta$-HSD1-expressing peripheral tissues, e.g., liver and adipose tissue. In addition to circulating cortisol levels, $11 \beta$ HSD1 expression in brain regulates the local availability of cortisol to bind to the glucocorticoid receptor (GR) in hypothalamus and the pituitary gland for negative feedback regulation (broken line). ACTH, adrenocorticotropic hormone; CRH, corticotropin-releasing hormone; GR, glucocorticoid receptor

$11 \beta$-HSD1 overexpression in preadipocytes for the development of visceral obesity remain obscure.

\section{Dysregulation of 11 $\beta$-HSD1 in human obesity}

Obesity seems to be associated with increased cortisol excretion [48] that correlates with BMI [49]. However, plasma cortisol concentration is not increased in obese subjects but is usually lower than in non-obese subjects, a finding that could relate to enhanced peripheral metabolism of cortisol in obesity. Increased plasma ACTH concentrations point to an increased hypothalamo-pituitary-adrenal (HPA) axis activity in obese subjects that could be due to a relative insensitivity to glucocorticoid feedback $[50,51]$ but alterations in HPA axis regulation in obesity are complex and cannot be discussed here in detail. Notably, 11ßHSD1 expression is also implicated in the central nervous system including local glucocorticoid production in key control sites for the HPA axis as shown by exaggerated plasma glucocorticoid responses to stress in $11 \beta$-HSD $1^{-/-}$mice [46] (Fig. 3).

An indication for a pathophysiological role of $11 \beta$ HSD1 in the generation of visceral adipose tissue in obesity could be derived from the description of a patient with biochemically proven Cushing's syndrome and concomitantly impaired cortisone to cortisol conversion who lacked the classical clinical phenotype including central obesity [52]. However, a defective $11 \beta$-HSD1 oxo-reductase activity does not necessarily have to cause a lean phenotype [53]. 
According to a number of previous studies, obesity is associated with tissue-specific dysregulation of $11 \beta$-HSD1 activity in humans [23]. Whereas whole body $11 \beta$-HSD1 activity (mainly reflecting hepatic expression) is down-regulated particularly in visceral obesity, activity in adipose tissue is increased in obese subjects [54]. These human studies have been confirmed by data from leptin-resistant obese Zucker rats [55]. Only subcutaneous adipose tissue could be investigated in human studies but not the metabolically important adipose tissue from visceral sites. Moreover, urinary metabolite ratios as used in some studies should be taken with caution as an indicator for $11 \beta$-HSD activity and do not correlate with BMI but only with the ratio of visceral to subcutaneous fat, e.g. as measured by computerised tomography [56]. Genetic analyses of microsatellite markers within the $11 \beta$-HSD1 gene showed associations with cortisol metabolite ratios and WHR indicating a possible contribution of $11 \beta$-HSD1 to the development particularly of visceral obesity. These data point to the necessity to evaluate the type of obesity when studying the pathophysiological role of $11 \beta$-HSD1 in adipose tissue.

Since $11 \beta$-HSD1 expression and activity differs in preadipocytes versus mature adipocytes, analysis of adipose tissue as a whole does not provide sufficient insight on its pathophysiological role. In situ hybridisation on adipose tissue of obese patients compared to lean control subjects showed increased 11 $\beta$-HSD1 mRNA expression in the adipocyte compartment of subcutaneous adipose tissue and in the visceral fat in both adipocytes and stroma [57]. These data confirm previous in vitro data from isolated preadipocytes and emphasise site-specific alterations of 11ß-HSD1 expression particularly in preadipocytes.

The tissue-specific dysregulation of $11 \beta$-HSD1 was seemingly contradicted by recent data analysing preadipocytes and adipocytes from visceral and subcutaneous adipose tissue samples derived from non-obese and obese patients [58]. 11 $\beta$-HSD1 mRNA expression and activity in preadipocytes from visceral origin was considerably lower exclusively in visceral preadipocytes from obese compared to non-obese subjects when cultured with cortisol, whereas no differences concerning tissue location and BMI were found when evaluating mature adipocytes. Moreover, 11ß-HSD1 mRNA expression evaluated by real-time RT-PCR in whole adipose tissue from omental and subcutaneous origin was unaltered in obese compared with lean subjects. Though these data could be taken as an argument against a pathophysiological role of $11 \beta-H S D 1$ in obesity they have to be interpreted with caution since the type of obesity (android or gynoid) remained undefined in the female population under study. Moreover, we do not have data on glucocorticoid sensitivity of preadipocytes and adipocytes in visceral and subcutaneous adipose tissue from obese versus lean sub- jects. A clue for explaining the pathophysiological importance of these data could lie in the nature of adipose tissue hypertrophy and a switch in the $11 \beta$-HSD1 reaction from $11 \beta$-dehydrogenase to oxo-reductase in visceral preadiocytes as discussed above (Fig. 2). Adipose tissue hypertrophy results not only from increased adipocyte size but also from an increased number of adipocytes that require proliferation of preadipocytes. Since cortisol inhibits omental preadipocyte proliferation, decreased $11 \beta-H S D 1$ mRNA levels and oxo-reductase activity in omental preadipocytes could result in enhanced proliferation and hence promote visceral adipose-tissue mass in obese patients. Preadipocytes cultured in the presence of cortisol start adipocyte differentiation that is associated with an increase of $11 \beta-H S D 1$ oxo-reductase activity. Hence, the blunted increase of $11 \beta$-HSD1 activity in cultured visceral preadipocytes from obese patients could indicate a higher threshold for the switch to oxo-reductase reaction during adipogenesis, leading to adipose tissue hypertrophy.

In conclusion, most available data show increased $11 \beta$-HSD1 expression and activity in visceral adipose tissue, at least in preadipocytes and possibly also in adipocytes, in obese patients compared to lean control subjects. However, patients with visceral obesity still have to be evaluated with methods reliably reflecting $11 \beta$-HSD1 expression in vivo.

\section{1 $\beta$-HSD1 and insulin resistance}

A number of cross-sectional studies have indicated that increased serum cortisol concentrations or 24-h urinary cortisol excretion is correlated with clinical manifestations of the metabolic syndrome (e.g. [59, $60,61]$ ) and might explain the association of low birth weight and insulin resistance [62]. Alterations in cortisol excretion and HPA axis regulation have specifically been observed in diabetes mellitus $[63,64,65,66$, 67]. A recent study involving moderately overweight Type 2 diabetic patients and control subjects matched for weight, height, BMI and blood pressure showed increased central and peripheral sensitivity to glucocorticoids in diabetic patients even if their metabolism was optimally controlled $\left(\mathrm{HbA}_{1 \mathrm{c}} \quad 6.9 \pm 0.2 \%\right.$ vs $6.0 \pm 0.1 \%$ ) [68]. Overall generation of cortisol from cortisone (reflecting mainly hepatic $11 \beta$-HSD1 activity) was impaired in diabetic patients but there were no differences in 11 $\beta$-HSD1 activity in subcutaneous fat biopsies. On the other hand, increased sensitivity to glucocorticoid action in the presence of unaltered glucocorticoid secretion in diabetic patients indicates an imbalance leading to inappropriately high glucocorticoid responses. Since the patients and control subjects were matched for weight in that study [68], changes in glucocorticoid activation and sensitivity in diabetes patients are beyond the dysregulation found in simple 
primary obesity. Thus, abnormalities in adipose tissue cortisol metabolism and/or glucocorticoid sensitivity could contribute to insulin resistance and thereby to the development of Type 2 diabetes and other manifestations of the metabolic syndrome.

In addition to $11 \beta$-HSD1 expression in adipose tissue, expression of glucocorticoid receptor $(\mathrm{GR} \alpha)$ and $11 \beta$-HSD1 in myoblasts is positively correlated with characteristics of the metabolic syndrome, namely insulin resistance, BMI and blood pressure [69]. Hence dysregulation of 11 $\beta$-HSD1 in muscle, the major target tissue of insulin action seems to parallel its regulation in adipose tissue in obesity and the metabolic syndrome.

Type 2 diabetes is characterised by disturbed insulin secretion in addition to decreased insulin sensitivity $[70,71]$. In contrast to the well-known secondary hyperinsulinaemia in response to acute cortisol exposure in healthy subjects [72], glucocorticoids even in physiological concentrations directly inhibit insulin secretion from pancreatic islets in vitro and in vivo $[10,73,74,75,76]$. 11ß-HSD1 is expressed in islet cells and 11-oxo glucocorticoids activated by $11 \beta$-HSD1 diminish insulin secretion [76]. Hence, $11 \beta$-HSD1 could interfere not only with peripheral insulin sensitivity but also with insulin secretion. Consequently, 11ß-HSD1 could be implicated not only in the development of visceral obesity but also in the deterioration of insulin sensitivity and in the dysregulation of insulin secretion resulting in Type 2 diabetes mellitus.

Studies with 11 $\beta$-HSD inhibitors. Pharmacological studies showed that inhibition of $11 \beta$-HSD1 exerts a positive effect on insulin sensitivity in diabetic subjects. This also applies to healthy subjects exposed to an unspecific $11 \beta-H S D$ inhibitor that blocks $11 \beta-H S D$ Type 1 and Type 2 as shown by euglycaemic, hyperinsulinaemic clamp studies [77]. In a recent doubleblind crossover study with the unspecific $11 \beta$-HSD inhibitor carbenoxolone, diet-controlled non-obese diabetic patients $\left(\mathrm{HbA}_{1 \mathrm{c}}<8 \%\right)$ and matched control subjects were evaluated by euglycaemic hyperinsulinaemic clamps with or without concomitant hyperglucagonaemia [78]. Unspecific inhibition of $11 \beta$ HSDs in Type 2 diabetic patients did not affect the glucose disposal rate or suppression of NEFA during hyperinsulinaemia, but reduced glycogenolysis and associated glucose production rate during hyperglucagonaemia. Though an effect on gluconeogenesis could not be shown, this study showed that even in nonobese patients with only little visceral adipose tissue, inhibition of $11 \beta$-HSD1 could exert beneficial effects on glucose homeostasis. Since most Type 2 diabetic patients are obese with predominant hypertrophy of visceral adipose tissue that highly expresses $11 \beta$ HSD1, inhibition or down-regulation of $11 \beta$-HSD1 could improve glycaemia.
In contrast to the use of unspecific 11 $\beta$-HSD inhibitors causing hypertension and hypokalaemia by inhibition of renal 11 $\beta$-HSD2, a selective inhibitor of murine 11ß-HSD1 (BVT.2733) has been shown in spontaneously hyperglycaemic $\mathrm{KKA}^{\mathrm{y}}$ mice to lower hepatic PEPCK and glucose-6-phosphatase mRNA expression as well as blood glucose and serum insulin concentrations [79]. Selective inhibitors of human $11 \beta$ HSD1 have already been synthesised [80]. These drugs could lower intrahepatic and intra-adipose tissue cortisol concentrations and thereby regionally enhance insulin sensitivity, reduce gluconeogenesis and potentially even adiposity. Though available metabolic data are still restricted to rodents they are highly promising for clinical studies to come in the near future.

Studies with selective $11 \beta$-HSD1 inhibitors will prove or disprove the concept of $11 \beta$-HSD1 contributing to the development of visceral obesity and Type 2 diabetes. However, if successful in their application, specific $11 \beta$-HSD1 inhibitors could be particularly beneficial for obese patients with insulin resistance syndrome and Type 2 diabetes. Since $11 \beta$-HSD1 expression is dysregulated in these disorders in a tissuespecific manner with high expression in adipose tissue but low activity in liver, clinical effects of selective $11 \beta$-HSD1 inhibitors could vary with their local concentration in adipose tissue and liver.

In addition to effects in metabolically active tissues, 11 $\beta$-HSD1-induced changes in the HPA axis have to be awaited since inhibition of central nervous system 11 $\beta$-HSD1 could disrupt negative HPA feedback regulation [46] (Fig. 3). 11 $\beta$-HSD1 is important for glucocorticoid activation also in the brain and regulates the HPA axis. Thus, inhibition of hypothalamic $11 \beta$-HSD1 could blunt negative feedback regulation by reducing local cortisol concentration and result in increased secretion of glucocorticoids from the adrenals. To avoid this hypothalamic interference by specific 11ß-HSD1 inhibitors such drugs should be unable to cross the blood brain barrier. On the other hand, 11 $\beta$-HSD1 inhibition in the central nervous system could protect the brain from the adverse effects of GCs that are proposed to occur during aging [81]. Thus $11 \beta$-HSD1 inhibitors have the potential of becoming an interesting novel class of drugs in the future even beyond the treatment of obesity and Type 2 diabetes.

Down-regulation of $11 \beta$-HSD1 expression. Besides pharmacological inhibition of $11 \beta$-HSD1 enzymatic activity, also down-regulation of the expression of the HSD11B1 gene could reduce local glucocorticoid activation. Several nuclear receptors have been shown to down-regulate $11 \beta$-HSD1 expression in adipocytes and/or liver through unknown molecular mechanisms. This applies to PPARs, which play important roles in metabolic regulation and adipocyte differentiation. PPAR $\gamma$ is mainly expressed in adipose tissue and its 
agonists, the thiazolidinediones, which are clinically applied to lower insulin resistance in Type 2 diabetic patients by widely unknown mechanisms [82, 83]. PPAR $\gamma$ agonists down-regulate $11 \beta$-HSD1 expression in adipose tissue and thereby decrease whole body cortisone to cortisol conversion in diabetic mice [38]. Thus, PPAR $\gamma$ agonists could mediate at least part of their beneficial effect on insulin sensitivity by downregulation of $11 \beta-H S D 1$. Also agonists of PPAR $\alpha$ mainly expressed in liver, down-regulate 11ß-HSD1 expression and activity in livers of wild-type but not of PPAR $\alpha^{-1-}$ mice [84]. However, PPAR $\alpha$ agonists do not have a relevant effect on insulin sensitivity in diabetic patients perhaps because hepatic 11 $\beta$-HSD1 expression appears already down-regulated in visceral obesity [23].

Very recently, treatment with a liver $\mathrm{X}$ receptor agonist was shown to down-regulate both $11 \beta$-HSD1 expression and activity in adipocytes and livers in wildtype but not in $\mathrm{LXR} \alpha^{-1-} \beta^{-/-}$mice in parallel with reduced PEPCK expression [85]. Moreover, LXR agonist treatment also decreased blood glucose concentrations in diabetic mice [86] though mechanisms other than down-regulation of $11 \beta-H S D 1$ could be responsible for that phenomenon [87, 88]. Nevertheless, both LXR as well as PPAR $\gamma$ agonists could mediate their anti-diabetic action at least in part via down-regulation of 11ß-HSD1. Although very promising, all data so far have been derived from mouse studies and it remains to be seen whether PPAR $\gamma$ and LXR agonists also repress $11 \beta$-HSD1 expression in humans.

\section{Conclusions}

Currently available data particularly in genetically altered mice suggest $11 \beta$-HSD1 to have a pathophysiological role in the development of obesity and in the insulin-resistance syndromes including Type 2 diabetes mellitus. Published data are derived from rodent model systems but not from studies on humans which are urgently needed to define the pharmacological potential of specific inhibitors of $11 \beta-H S D 1$ for the treatment of visceral obesity and the metabolic syndrome. The situation has recently changed by introduction of specific $11 \beta$-HSD1 inhibitors with selectivity for mice and humans, respectively [80]. A specific inhibitor for murine 11 $\beta$-HSD1 has been successfully applied in diabetic mice. Clinical studies with these potential drugs are needed to decide on the concept of the $11 \beta$-HSD1 blockade as a novel mode of treatment for patients with obesity or Type 2 diabetes.

\section{Sources}

For this review literature was extracted from Medline (PubMed) until September 10, 2003 using the frag- ments 11beta-hydroxysteroid, 11beta-HSD1, and 11 beta-HSD-1 to occur in any field.

Acknowledgements. We are very grateful to Prof. U. Oppermann, Karolinska Institute, Stockholm, Sweden, for intense discussions on the subject and critical review of the manuscript. This work was supported by CeMM-Center of Molecular Medicine, a basic research institute within the companies of the Austrian Academy of Sciences (to T. Stulnig and W. Waldhäusl).

\section{References}

1. Reaven GM, Hoffman BB (1987) A role for insulin in the aetiology and course of hypertension? Lancet 2:435-437

2. DeFronzo RA, Ferrannini E (1991) Insulin resistance. A multifaceted syndrome responsible for NIDDM, obesity, hypertension, dyslipidemia, and atherosclerotic cardiovascular disease. Diabetes Care 14:173-194

3. Waldhäusl WK, Roden MD (2000) The effects of free fatty acids on glucose transport and phosphorylation in human skeletal muscle. Curr Opin Endocrinol Metabol 7:211-216

4. Montague CT, O'Rahilly S (2000) The perils of portliness: causes and consequences of visceral adiposity. Diabetes 49:883-888

5. Gabriely I, Ma XH, Yang XM et al. (2002) Removal of visceral fat prevents insulin resistance and glucose intolerance of aging: an adipokine-mediated process? Diabetes 51:2951-2958

6. Rebuffe-Scrive M, Bronnegard M, Nilsson A, Eldh J, Gustafsson JA, Bjorntorp P (1990) Steroid hormone receptors in human adipose tissues. J Clin Endocrinol Metab $71: 1215-1219$

7. Bujalska IJ, Kumar S, Stewart PM (1997) Does central obesity reflect "Cushing's disease of the omentum"? Lancet 349:1210-1213

8. Hasselgren PO (1999) Glucocorticoids and muscle catabolism. Curr Opin Clin Nutr Metab Care 2:201-205

9. Brindley DN (1995) Role of glucocorticoids and fatty acids in the impairment of lipid metabolism observed in the metabolic syndrome. Int J Obes Relat Metab Disord 19 [Suppl 1]:S69-S75

10. Lambillotte C, Gilon P, Henquin JC (1997) Direct glucocorticoid inhibition of insulin secretion. An in vitro study of dexamethasone effects in mouse islets. J Clin Invest 99:414-423

11. Andrews RC, Walker BR (1999) Glucocorticoids and insulin resistance: old hormones, new targets. Clin Sci (Lond) 96:513-523

12. Hanson RW, Reshef L (1997) Regulation of phosphoenolpyruvate carboxykinase (GTP) gene expression. Annu Rev Biochem 66:581-611

13. Yoon JC, Puigserver P, Chen G et al. (2001) Control of hepatic gluconeogenesis through the transcriptional coactivator PGC-1. Nature 413:131-138

14. Herzig S, Long F, Jhala US et al. (2001) CREB regulates hepatic gluconeogenesis through the coactivator PGC-1. Nature 413:179-183

15. Dimitriadis G, Leighton B, Parry-Billings M et al. (1997) Effects of glucocorticoid excess on the sensitivity of glucose transport and metabolism to insulin in rat skeletal muscle. Biochem J 321:707-712

16. Nosadini R, Del Prato S, Tiengo A et al. (1983) Insulin resistance in Cushing's syndrome. J Clin Endocrinol Metab 57:529-536 
17. Olefsky JM, Kimmerling G (1976) Effects of glucocorticoids on carbohydrate metabolism. Am J Med Sci 271:202-210

18. Vestergaard H, Bratholm P, Christensen NJ (2001) Increments in insulin sensitivity during intensive treatment are closely correlated with decrements in glucocorticoid receptor mRNA in skeletal muscle from patients with Type II diabetes. Clin Sci (Lond) 101:533-540

19. Nobel S, Abrahmsen L, Oppermann U (2001) Metabolic conversion as a pre-receptor control mechanism for lipophilic hormones. Eur J Biochem 268:4113-4125

20. Oppermann UC, Persson B, Jornvall H (1997) Function, gene organization and protein structures of 11beta-hydroxysteroid dehydrogenase isoforms. Eur J Biochem 249:355-360

21. Stewart PM, Krozowski ZS (1999) 11 beta-Hydroxysteroid dehydrogenase. Vitam Horm 57:249-324

22. Walker BR, Campbell JC, Fraser R, Stewart PM, Edwards CR (1992) Mineralocorticoid excess and inhibition of 11 beta-hydroxysteroid dehydrogenase in patients with ectopic ACTH syndrome. Clin Endocrinol (Oxf) 37:483-492

23. Sandeep TC, Walker BR (2001) Pathophysiology of modulation of local glucocorticoid levels by 11betahydroxysteroid dehydrogenases. Trends Endocrinol Metab 12:446-453

24. Jamieson PM, Chapman KE, Edwards CR, Seckl JR (1995) 11 beta-hydroxysteroid dehydrogenase is an exclusive 11 beta- reductase in primary cultures of rat hepatocytes: effect of physicochemical and hormonal manipulations. Endocrinology 136:4754-4761

25. Bujalska IJ, Kumar S, Hewison M, Stewart PM (1999) Differentiation of adipose stromal cells: the roles of glucocorticoids and 11 beta-hydroxysteroid dehydrogenase. Endocrinology 140:3188-3196

26. Hauner H, Schmid P, Pfeiffer EF (1987) Glucocorticoids and insulin promote the differentiation of human adipocyte precursor cells into fat cells. J Clin Endocrinol Metab 64:832-835

27. Bähr V, Pfeiffer AF, Diederich S (2002) The metabolic syndrome $\mathrm{X}$ and peripheral cortisol synthesis. Exp Clin Endocrinol Diabetes 110:313-318

28. Oakley RH, Cidlowski JA (1993) Homologous down regulation of the glucocorticoid receptor: the molecular machinery. Crit Rev Eukaryot Gene Expr 3:63-88

29. Bamberger CM, Schulte HM, Chrousos GP (1996) Molecular determinants of glucocorticoid receptor function and tissue sensitivity to glucocorticoids. Endocr Rev 17:245-261

30. Hammami MM, Siiteri PK (1991) Regulation of 11 betahydroxysteroid dehydrogenase activity in human skin fibroblasts: enzymatic modulation of glucocorticoid action. $\mathbf{J}$ Clin Endocrinol Metab 73:326-334

31. Voice MW, Seckl JR, Edwards CR, Chapman KE (1996) 11 beta-hydroxysteroid dehydrogenase type 1 expression in $2 \mathrm{~S}$ FAZA hepatoma cells is hormonally regulated: a model system for the study of hepatic glucocorticoid metabolism. Biochem J 317:621-625

32. Moore JS, Monson JP, Kaltsas G et al. (1999) Modulation of 11 beta-hydroxysteroid dehydrogenase isozymes by growth hormone and insulin-like growth factor: in vivo and in vitro studies. J Clin Endocrinol Metab 84:4172-4177

33. Tomlinson JW, Moore J, Cooper MS et al. (2001) Regulation of expression of 11 beta-hydroxysteroid dehydrogenase type 1 in adipose tissue: tissue-specific induction by cytokines. Endocrinology 142:1982-1989

34. Handoko K, Yang K, Strutt B, Khalil W, Killinger D (2000) Insulin attenuates the stimulatory effects of tumor necrosis factor alpha on 11 beta-hydroxysteroid dehydrogenase 1 in human adipose stromal cells. J Steroid Biochem Mol Biol 72:163-168
35. Jamieson PM, Nyirenda MJ, Walker BR, Chapman KE, Seckl JR (1999) Interactions between oestradiol and glucocorticoid regulatory effects on liver-specific glucocorticoid-inducible genes: possible evidence for a role of hepatic 11 beta-hydroxysteroid dehydrogenase type 1 . J Endocrinol 160:103-109

36. Moisan MP, Edwards CR, Seckl JR (1992) Differential promoter usage by the rat 11 beta-hydroxysteroid dehydrogenase gene. Mol Endocrinol 6:1082-1087

37. Williams LJ, Lyons V, MacLeod I et al. (2000) C/EBP regulates hepatic transcription of 11 beta -hydroxysteroid dehydrogenase type 1 . A novel mechanism for cross-talk between the $\mathrm{C} / \mathrm{EBP}$ and glucocorticoid signaling pathways. J Biol Chem 275:30232-30239

38. Berger J, Tanen M, Elbrecht A et al. (2001) Peroxisome proliferator-activated receptor-gamma ligands inhibit adipocyte 11 beta -hydroxysteroid dehydrogenase type 1 expression and activity. J Biol Chem 276:12629-12635

39. Bujalska IJ, Walker EA, Hewison M, Stewart PM (2002) A switch in dehydrogenase to reductase activity of 11 betahydroxysteroid dehydrogenase type 1 upon differentiation of human omental adipose stromal cells. J Clin Endocrinol Metab 87:1205-1210

40. Napolitano A, Voice MW, Edwards CR, Seckl JR, Chapman KE (1998) 11Beta-hydroxysteroid dehydrogenase 1 in adipocytes: expression is differentiation-dependent and hormonally regulated. J Steroid Biochem Mol Biol 64:251-260

41. Draper N, Walker EA, Bujalska IJ et al. (2003) Mutations in the genes encoding 11 beta-hydroxysteroid dehydrogenase type 1 and hexose-6-phosphate dehydrogenase interact to cause cortisone reductase deficiency. Nat Genet 34:434-439

42. Rabbitt EH, Lavery GG, Walker EA, Cooper MS, Stewart PM, Hewison M (2002) Prereceptor regulation of glucocorticoid action by 11 beta-hydroxysteroid dehydrogenase: a novel determinant of cell proliferation. FASEB J 16:36-44

43. Masuzaki H, Paterson J, Shinyama H et al. (2001) A transgenic model of visceral obesity and the metabolic syndrome. Science 294:2166-2170

44. Bujalska IJ, Walker EA, Tomlinson JW, Hewison M, Stewart PM (2002) 11Beta-hydroxysteroid dehydrogenase type 1 in differentiating omental human preadipocytes: from de-activation to generation of cortisol. Endocr Res 28:449-461

45. Kotelevtsev Y, Holmes MC, Burchell A et al. (1997) 11beta-Hydroxysteroid dehydrogenase type 1 knockout mice show attenuated glucocorticoid-inducible responses and resist hyperglycemia on obesity or stress. Proc Natl Acad Sci USA 94:14924-14929

46. Harris HJ, Kotelevtsev Y, Mullins JJ, Seckl JR, Holmes MC (2001) Intracellular regeneration of glucocorticoids by 11beta-hydroxysteroid dehydrogenase (11beta-HSD)-1 plays a key role in regulation of the hypothalamic-pituitary-adrenal axis: analysis of 11beta-HSD-1-deficient mice. Endocrinology 142:114-120

47. Morton NM, Holmes MC, Fievet C et al. (2001) Improved lipid and lipoprotein profile, hepatic insulin sensitivity and glucose tolerance in 11 \{beta\}-hydroxysteroid dehydrogenase type 1 null mice. J Biol Chem 276:41293-41300

48. Dunkelman SS, Fairhurst B, Plager J, Waterhouse C (1964) Cortisol metabolism in obesity. J Clin Endocrinol 24: 832-841

49. Fraser R, Ingram MC, Anderson NH, Morrison C, Davies E, Connell JM (1999) Cortisol effects on body mass, blood pressure, and cholesterol in the general population. Hypertension 33:1364-1368 
50. Bjorntorp P (1995) Endocrine abnormalities of obesity. Metabolism 44:21-23

51. Jessop DS, Dallman MF, Fleming D, Lightman SL (2001) Resistance to glucocorticoid feedback in obesity. J Clin Endocrinol Metab 86:4109-4114

52. Tomlinson JW, Draper N, Mackie J et al. (2002) Absence of Cushingoid phenotype in a patient with Cushing's disease due to defective cortisone to cortisol conversion. J Clin Endocrinol Metab 87:57-62

53. Jamieson A, Wallace AM, Andrew R et al. (1999) Apparent cortisone reductase deficiency: a functional defect in 11 beta-hydroxysteroid dehydrogenase type 1. J Clin Endocrinol Metab 84:3570-3574

54. Stewart PM, Boulton A, Kumar S, Clark PM, Shackleton $\mathrm{CH}$ (1999) Cortisol metabolism in human obesity: impaired cortisone $\rightarrow$ cortisol conversion in subjects with central adiposity. J Clin Endocrinol Metab 84:1022-1027

55. Livingstone DE, Jones GC, Smith K et al. (2000) Understanding the role of glucocorticoids in obesity: tissue-specific alterations of corticosterone metabolism in obese Zucker rats. Endocrinology 141:560-563

56. Tiosano D, Eisentein I, Militianu D, Chrousos GP, Hochberg Z (2003) 11beta-hydroxysteroid dehydrogenase activity in hypothalamic obesity. J Clin Endocrinol Metab 88:379-384

57. Paulmyer-Lacroix O, Boullu S, Oliver C, Alessi MC, Grino M (2002) Expression of the mRNA coding for 11beta-hydroxysteroid dehydrogenase type 1 in adipose tissue from obese patients: an in situ hybridization study. J Clin Endocrinol Metab 87:2701-2705

58. Tomlinson JW, Sinha B, Bujalska I, Hewison M, Stewart PM (2002) Expression of 11beta-hydroxysteroid dehydrogenase type 1 in adipose tissue is not increased in human obesity. J Clin Endocrinol Metab 87:5630-5635

59. Filipovsky J, Ducimetiere P, Eschwege E, Richard JL, Rosselin G, Claude JR (1996) The relationship of blood pressure with glucose, insulin, heart rate, free fatty acids and plasma cortisol levels according to degree of obesity in middle-aged men. J Hypertens 14:229-235

60. Hautanen A, Raikkonen K, Adlercreutz H (1997) Associations between pituitary-adrenocortical function and abdominal obesity, hyperinsulinaemia and dyslipidaemia in normotensive males. J Intern Med 241:451-461

61. Walker BR, Phillips DI, Noon JP et al. (1998) Increased glucocorticoid activity in men with cardiovascular risk factors. Hypertension 31:891-895

62. Phillips DI, Barker DJ, Fall CH et al. (1998) Elevated plasma cortisol concentrations: a link between low birth weight and the insulin resistance syndrome? J Clin Endocrinol Metab 83:757-760

63. Kaye TB, Rubin RA, Goldfine AB et al. (1992) Effect of glycemic control on the overnight dexamethasone suppression test in patients with diabetes mellitus. J Clin Endocrinol Metab 74:640-644

64. Roy MS, Roy A, Brown S (1998) Increased urinary-free cortisol outputs in diabetic patients. J Diabetes Complications 12:24-27

65. Tsigos C, Young RJ, White A (1993) Diabetic neuropathy is associated with increased activity of the hypothalamicpituitary-adrenal axis. J Clin Endocrinol Metab 76: 554-558

66. Mortimore GE, Irvine E, Hopper J, Forsham PH (1956) The functional state of the adrenal cortex in diabetes mellitus. J Clin Endocrinol 16:932-936

67. Kerstens MN, Riemens SC, Sluiter WJ, Pratt JJ, Wolthers BG, Dullaart RP (2000) Lack of relationship between 11beta-hydroxysteroid dehydrogenase setpoint and insulin sensitivity in the basal state and after $24 \mathrm{~h}$ of insulin infu- sion in healthy subjects and type 2 diabetic patients. Clin Endocrinol (Oxf) 52:403-411

68. Andrews RC, Herlihy O, Livingstone DE, Andrew R, Walker BR (2002) Abnormal cortisol metabolism and tissue sensitivity to cortisol in patients with glucose intolerance. J Clin Endocrinol Metab 87:5587-5593

69. Whorwood CB, Donovan SJ, Flanagan D, Phillips DI, Byrne CD (2002) Increased glucocorticoid receptor expression in human skeletal muscle cells may contribute to the pathogenesis of the metabolic syndrome. Diabetes 51:1066-1075

70. Waldhäusl W, Bratusch-Marrain P, Gasic S, Korn A, Nowotny P (1982) Insulin production rate, hepatic insulin retention and splanchnic carbohydrate metabolism after oral glucose ingestion in hyperinsulinaemic Type 2 (noninsulin-dependent) diabetes mellitus. Diabetologia 23:6-15

71. Kahn SE (2003) The relative contributions of insulin resistance and beta-cell dysfunction to the pathophysiology of type 2 diabetes. Diabetologia 46:3-19

72. Waldhäusl WK, Gasic S, Bratusch-Marrain P, Komjati M, Korn A (1987) Effect of stress hormones on splanchnic substrate and insulin disposal after glucose ingestion in healthy humans. Diabetes 36:127-135

73. Dinneen S, Alzaid A, Miles J, Rizza R (1993) Metabolic effects of the nocturnal rise in cortisol on carbohydrate metabolism in normal humans. J Clin Invest 92:22832290

74. Delaunay F, Khan A, Cintra A et al. (1997) Pancreatic beta cells are important targets for the diabetogenic effects of glucocorticoids. J Clin Invest 100:2094-2098

75. Ling ZC, Khan A, Delauny F et al. (1998) Increased glucocorticoid sensitivity in islet beta-cells: effects on glucose 6-phosphatase, glucose cycling and insulin release. Diabetologia 41:634-639

76. Davani B, Khan A, Hult M et al. (2000) Type 111 beta-hydroxysteroid dehydrogenase mediates glucocorticoid activation and insulin release in pancreatic islets. J Biol Chem 275:34841-34844

77. Walker BR, Connacher AA, Lindsay RM, Webb DJ, Edwards CR (1995) Carbenoxolone increases hepatic insulin sensitivity in man: a novel role for 11-oxosteroid reductase in enhancing glucocorticoid receptor activation. J Clin Endocrinol Metab 80:3155-3159

78. Andrews RC, Rooyackers O, Walker BR (2003) Effects of the 11beta-hydroxysteroid dehydrogenase inhibitor carbenoxolone on insulin sensitivity in men with type 2 diabetes. J Clin Endocrinol Metab 88:285-291

79. Alberts P, Engblom L, Edling N et al. (2002) Selective inhibition of 11 beta-hydroxysteroid dehydrogenase type 1 decreases blood glucose concentrations in hyperglycaemic mice. Diabetologia 45:1528-1532

80. Barf T, Vallgarda J, Emond R et al. (2002) Arylsulfonamidothiazoles as a new class of potential antidiabetic drugs. Discovery of potent and selective inhibitors of the 11betahydroxysteroid dehydrogenase type 1 . J Med Chem 45: 3813-3815

81. Yau JL, Noble J, Kenyon CJ et al. (2001) Lack of tissue glucocorticoid reactivation in 11 beta -hydroxysteroid dehydrogenase type 1 knockout mice ameliorates age-related learning impairments. Proc Natl Acad Sci USA 98: 4716-4721

82. Spiegelman BM (1998) PPAR-gamma: Adipogenic regulator and thiazolidinedione receptor. Diabetes 47:507-514

83. Fürnsinn C, Waldhäusl W (2002) Thiazolidinediones: metabolic actions in vitro. Diabetologia 45:1211-1223

84. Hermanowski-Vosatka A, Gerhold D, Mundt SS et al. (2000) PPARalpha agonists reduce 11beta-hydroxysteroid 
dehydrogenase type 1 in the liver. Biochem Biophys Res Commun 279:330-336

85. Stulnig TM, Oppermann U, Steffensen KR, Schuster GU, Gustafsson JA (2002) Liver X receptors downregulate 11 beta-hydroxysteroid dehydrogenase type 1 expression and activity. Diabetes 51:2426-2433

86. Cao G, Liang Y, Broderick CL et al. (2003) Antidiabetic action of a liver $\mathrm{X}$ receptor agonist mediated by inhibition of hepatic gluconeogenesis. J Biol Chem 278:1131-1136
87. Stulnig TM, Steffensen KR, Gao H et al. (2002) Novel roles of liver $\mathrm{X}$ receptors exposed by gene expression profiling in liver and adipose tissue. Mol Pharmacol 62:1299-1305

88. Laffitte BA, Chao LC, Li J et al. (2003) Activation of liver $\mathrm{X}$ receptor improves glucose tolerance through coordinate regulation of glucose metabolism in liver and adipose tissue. Proc Natl Acad Sci USA 100:5419-5424 